\title{
PRODUTIVIDADE DO TRATOR FLORESTAL CHOCKER SKIDDER NA EXTRAÇÃO DE MADEIRA EM TERRENOS DECLIVOSOS
}

\author{
Eduardo da Silva Lopes ${ }^{1 *}$, Carlos Cézar Cavassin Diniz ${ }^{2}$ \\ ${ }^{1 *}$ Universidade Estadual do Centro-Oeste, Departamento de Engenharia Florestal, Irati, Paraná, Brasil - eslopes@ pq.cnpq.br \\ ${ }^{2}$ Universidade Estadual do Centro-Oeste, Curso de Engenharia Florestal, Irati, Paraná, Brasil - carloscezardiniz@gmail.com
}

Recebido para publicação: 05/05/2014 - Aceito para publicação: 01/05/2015

\begin{abstract}
Resumo
Este trabalho objetivou analisar os tempos do ciclo operacional e a produtividade do trator florestal chocker skidder na extração de madeira em diferentes classes de declividade e distância, visando gerar informações para o planejamento eficiente das operações e o melhor aproveitamento dos recursos disponíveis. O trabalho foi realizado em uma empresa florestal localizada no município de Itararé, SP. Foi realizado um estudo de tempos e movimentos do ciclo operacional, determinando disponibilidade mecânica, disponibilidade técnica, eficiência operacional e produtividade da máquina em diferentes condições de distância de extração e declividade do terreno. Os resultados indicaram que as atividades que consumiram a maior parte do tempo do ciclo de trabalho foram o "arraste do cabo e engate" e "desengate das correntes", com $28 \%$ e $11 \%$ do tempo total, respectivamente. Houve redução da produtividade da máquina com o aumento da declividade do terreno, sendo mais evidente nas menores distâncias de extração e mostrando a sensibilidade dessa variável nessa condição operacional.

Palavras-chave: Colheita de madeira; planejamento operacional; otimização.
\end{abstract}

\begin{abstract}
Productivity of forestry tractor chocker skidder in extraction of wood on steep terrain. The objective of this study was to evaluate the time consumed by the elements of the work cycle and the productivity of a chocker skidder in extraction of wood at different slope terrain and distances classes, generating information for efficient planning of operations and better utilization of available resources. The study was conducted in a forestry company located in the municipality of Itararé, São Paulo State. A motion and time study of the operational cycle was performed, determining the mechanical availability, technical availability, operational efficiency and productivity of the machine in different conditions of extraction distance and terrain slope. The results showed that elements of the work cycle which most time consuming were the "drag cable and engagement" and "disengagement of the currents" that consumed the greatest operational cycle of the machine with $28 \%$ and $11 \%$ of the total time, respectively. A reduction machine productivity with increasing of the terrain slope, being stronger in the smaller extraction distances and, showing the sensitivity of this variable in this operating condition.

Keywords: Timber harvesting; operational planning; optimization.
\end{abstract}

\section{INTRODUÇÃO}

As operações de colheita e transporte, que representam $50 \%$ ou mais do custo final da madeira posta na indústria, são influenciadas por diversos fatores técnicos, econômicos, ambientais e ergonômicos (LOPES, 2001; MACHADO, 2014). Por isso, o aperfeiçoamento das técnicas de colheita da madeira torna-se cada vez mais necessário para o aumento da eficiência operacional e da produtividade e redução dos custos de produção, contribuindo para a melhoria do processo produtivo e maior competitividade das empresas florestais (SILVA et al., 2003; BRAMUCCI; SEIXAS, 2014).

Na colheita de madeira, destaca-se a operação de extração, que consiste na remoção da madeira, na forma de toras, fustes ou árvores inteiras, do interior do povoamento para a margem do talhão, estrada ou pátio intermediário. É considerada a etapa de maior complexidade, exigindo um planejamento rigoroso, devido à influência de diversos fatores que afetam diretamente a produtividade e os custos de produção, como distância de extração, declividade do terreno, densidade do talhão, características do

FLORESTA, Curitiba, PR, v. 45, n. 3, p. 625 - 634, jul. / set. 2015.

Lopes, E. da S.; Diniz, C. C. C.

ISSN eletrônico 1982-4688 / ISSN impresso 0015-3826

625

DOI: $10.5380 /$ rf.v45i3.36409 
povoamento, tipo de máquina e nível de experiência do operador (OLIVEIRA et al., 2009; SANTOS et al., 2013; SEIXAS, 2014).

Studier e Binkley (1974) afirmam que a operação de extração de madeira torna-se mais complexa quando realizada em terrenos declivosos, sendo, atualmente, um grande desafio para as empresas florestais brasileiras, exigindo um planejamento rigoroso e o uso de máquinas e equipamentos específicos para uso nessas condições operacionais, capazes de aliar os elevados custos envolvidos e as interferências no meio ambiente. Para uso nessas condições de terreno, existem diversas opções de equipamentos disponíveis no mercado, podendo-se destacar os sistemas de cabos aéreos, os guinchos de tração e os balões e helicópteros, que podem ser utilizados em áreas com até 100\% de declividade.

No caso específico dos sistemas de cabos aéreos, apesar do elevado custo operacional, podem ser considerados uma opção eficiente do ponto de vista técnico e ambiental, pela sua aplicabilidade em regiões montanhosas onde há maior dificuldade na abertura de estradas, pelo baixo contato da madeira com o terreno durante a extração e pelo baixo investimento financeiro despendido na aquisição de alguns modelos desse equipamento (SIMÕES et al., 2010). Já os guinchos de tração montados em tratores agrícolas são opções de baixo custo utilizadas em algumas regiões do país, porém existem muitas discussões em relação aos danos causados ao meio ambiente, pois potencializam a degradação dos solos pela abertura de sulcos ao longo das trilhas no momento do arraste da madeira, deixando o terreno desprotegido e sujeito a sofrer processos erosivos.

Por isso, em função da complexidade da extração de madeira em terrenos declivosos, dos elevados custos, dos danos ao meio ambiente e da expansão das áreas florestais nessas, muitas empresas têm buscado novas alternativas de extração de madeira que sejam viáveis em relação aos aspectos técnico, econômico e ambiental (SILVA et al., 2003; ROCHA et al., 2009).

Entre as opções recentemente disponíveis no mercado, destaca-se o trator florestal forwarder, equipado com guincho de tração auxiliar, e o trator florestal arrastador skidder de cabo (chocker skidder), equipado com cabo auxiliar. Entretanto, como não existem informações a respeito da real capacidade produtiva desses equipamentos na extração da madeira em terrenos declivosos, torna-se necessária a realização de estudos para obtenção de informações para o desenvolvimento de técnicas que melhorem o desempenho operacional e a redução dos custos de produção.

Este trabalho objetivou analisar os tempos do ciclo operacional e a produtividade do trator florestal skidder de cabo na extração de madeira em terrenos declivosos, gerando informações para o planejamento das operações, aumento de produtividade e redução dos custos de produção.

\section{MATERIAL E MÉTODOS}

\section{Área de estudo}

O estudo foi realizado nas áreas de colheita da madeira de uma empresa florestal localizada no município de Itararé, estado de São Paulo. A região está situada entre as coordenadas geográficas $24^{\circ} 6^{\prime} 18^{\prime \prime} \mathrm{S}$ e $49^{\circ} 20^{\prime} 35^{\prime \prime} \mathrm{W}$, com uma altitude média de $772 \mathrm{~m}$. Os dados foram coletados durante o mês de julho de 2013, em plantios de Pinus taeda L., sendo a madeira produzida destinada para a indústria de MDF (Medium Density FiberBoard - Painéis de Fibra de Média Densidade).

As características do povoamento florestal estudado são descritas na tabela 1.

Tabela 1. Características do povoamento florestal estudado.

Table 1. Characteristics of forest stand studied.

\begin{tabular}{lc}
\hline Características do povoamento & Informações \\
\hline Espécie plantada & Pinus taeda $\mathrm{L}$. \\
Tipo de solo & Latossolo Vermelho \\
Relevo & Montanhoso \\
Regime de manejo & Corte raso \\
Idade do povoamento (anos) & 39 \\
Densidade de árvores do povoamento $\left(\mathrm{ha}^{-1}\right)$ & 541 \\
Área basal do povoamento $\left(\mathrm{m}^{2} . \mathrm{ha}^{-1}\right)$ & 52,4 \\
Diâmetro médio das árvores $(\mathrm{DAP})(\mathrm{cm})$ & 34,5 \\
Altura média das árvores $(\mathrm{m})$ & 29,1 \\
Volume médio individual das árvores $\left(\mathrm{m}^{3}\right)$ & 1,088 \\
\hline
\end{tabular}

FLORESTA, Curitiba, PR, v. 45, n. 3, p. 625 - 634, jul. / set. 2015. Lopes, E. da S.; Diniz, C. C. C. 


\section{Sistema de colheita da madeira}

O sistema de colheita da madeira utilizado pela empresa foi de árvores inteiras (full tree), sendo a derrubada das árvores realizada por equipes de operadores de motosserra, que deixavam, sempre que possível, as árvores agrupadas no interior do talhão no formato "espinha de peixe", de modo a facilitar a posterior extração da madeira. Em seguida, a extração das árvores do interior do talhão até a margem da estrada era realizada por um trator florestal skidder de cabo (chocker skidder) (Figura 1), e, por fim, era realizado o processamento da madeira em toras por operadores de motosserra.

Foi estudado o trator florestal skidder de cabo, da marca Caterpillar, modelo 525, com motor Cat C7 ACERT, potência bruta de $182 \mathrm{Hp}$, peso operacional de $16.000 \mathrm{~kg}$, rodados de pneus com tração $4 \times 4$, guincho equipado com cabos de diâmetro de 3/4", comprimento de $110 \mathrm{~m}$ e tração máxima de 183,5 kN.

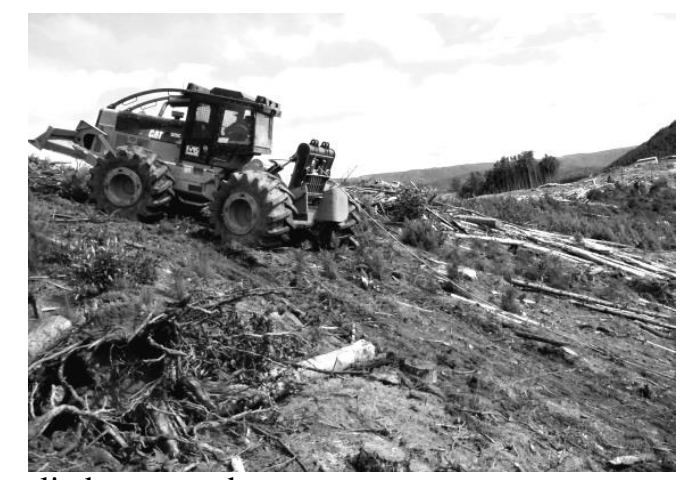

Figura 1. Skidder de cabo avaliado no estudo.

Figure 1. Chocker skidder evaluated in this work.

\section{Procedimento de amostragem}

Inicialmente, realizou-se um estudo piloto para definição do número mínimo de observações necessárias (ciclos operacionais), utilizando-se a metodologia proposta por Barnes (1977), de modo a proporcionar um erro de amostragem máximo de 5\%, por meio da seguinte expressão:

$$
\mathrm{n} \geq \frac{\mathrm{t}^{2} \times \mathrm{CV}^{2}}{\mathrm{E}^{2}}
$$

em que: $\mathrm{n}=$ número mínimo de ciclos necessários; $\mathrm{t}$ = valor de $\mathrm{t}$, para o nível de probabilidade desejado e (n-1) graus de liberdade; $\mathrm{CV}$ = coeficiente de variação, em porcentagem; $\mathrm{E}=$ erro admissível, em porcentagem.

\section{Coleta de dados}

A coleta de dados baseou-se na realização de um estudo de tempos e movimentos, visando a análise do ciclo operacional e a determinação da disponibilidade mecânica, da disponibilidade técnica, da eficiência operacional e da produtividade da máquina na operação de extração da madeira, contemplando diferentes classes de declividade do terreno e distâncias de extração.

A obtenção de disponibilidade mecânica, disponibilidade técnica e eficiência operacional da máquina objetivou verificar a influência das variáveis operacionais no comportamento dos parâmetros técnicos, de modo a subsidiar o planejamento da operação para aumento de produtividade e redução dos custos de produção.

\section{Estudo de tempos e movimentos}

O estudo de tempos e movimentos da operação de extração da madeira foi realizado empregando-se o método de cronometragem de tempos contínuos, caracterizado pela medição do tempo sem a detenção do cronômetro, ou seja, de forma contínua. No estudo, foi utilizado um cronômetro centesimal, prancheta e formulários de campo específicos desenvolvidos para esta finalidade. parciais:

O ciclo operacional da extração com o skidder de cabo foi subdividido nos seguintes elementos

- Viagem vazio (VV): Iniciava no momento em que a máquina começava a se deslocar da margem da estrada (estaleiro) em direção ao interior do talhão e terminava com a sua parada no local limite de 
acesso, em média, localizado a 25 metros da margem do talhão.

- Arraste do cabo e engate das correntes (AE): Iniciava no momento em que o auxiliar apanhava o cabo de arraste na máquina e terminava com o engate do cabo nas correntes auxiliares previamente fixadas por outro auxiliar nas bases das árvores previamente derrubadas.

- Guinchamento (GC): Iniciava com o guinchamento das árvores pela máquina do ponto de engate no interior do talhão e terminava com o posicionamento das árvores no formato de feixes junto à máquina, estacionada no local limite de acesso no interior do talhão.

- Viagem carregado (VC): Iniciava com o deslocamento da máquina arrastando o feixe de árvores e terminava com a parada na margem da estrada ou estaleiro.

- Desengate das correntes (DG): Iniciava com a parada da máquina na margem da estrada ou estaleiro e terminava com o desengate do feixe de árvores realizado por um auxiliar.

- Manobra da máquina e arrumação da carga $(\mathrm{AB})$ : Iniciava com a manobra da máquina visando a organização das árvores arrastadas no estaleiro e terminava com o deslocamento da máquina para início do próximo ciclo operacional.

Foram ainda consideradas as interrupções operacionais e não operacionais e suas respectivas causas e consequências.

\section{Disponibilidade mecânica, disponibilidade técnica e eficiência operacional}

A disponibilidade mecânica é definida como a percentagem de tempo de trabalho programado em que a máquina esteve mecanicamente apta a realizar trabalho produtivo, desconsiderando-se os tempos em manutenção preventiva e/ou corretiva, obtida pela seguinte expressão, adaptada de Santos et al. (2013):

$$
\mathrm{DM}=\frac{\mathrm{TP}-\mathrm{TM}}{\mathrm{TP}} \times 100
$$

em que: $\mathrm{DM}=$ disponibilidade mecânica (\%); TP = tempo programado para o trabalho (horas);

$\mathrm{TM}=$ tempo em manutenção preventiva e corretiva (horas).

A disponibilidade técnica é a percentagem de tempo em que a máquina executa a operação de forma efetiva, desconsiderando os tempos de interrupções operacionais e não operacionais, ou seja, a relação entre o tempo de trabalho efetivo e o tempo disponível da máquina para o trabalho, obtida pela seguinte expressão:

$$
\mathrm{DT}=\frac{\mathrm{TD}-\mathrm{TI}}{\mathrm{TD}} \times 100
$$

em que: $\mathrm{DT}=$ disponibilidade técnica $(\%)$;D = tempo disponível para o trabalho, desconsiderando-se as paradas para manutenção (horas); TI = tempo de interrupções operacionais e não operacionais (horas).

A eficiência operacional é a percentagem de tempo de trabalho em que a máquina executou a operação de forma efetiva, desconsiderando os tempos em manutenção e as interrupções operacionais e não operacionais, obtida pela seguinte expressão adaptada de Santos et al. (2013):

$$
\mathrm{EO}=\frac{\mathrm{TE}}{\mathrm{TP}} \times 100
$$

em que: $\mathrm{EO}=$ eficiência operacional $(\%)$; $\mathrm{TE}=$ tempo de trabalho efetivo, desconsiderando-se as paradas para manutenção e interrupções operacionais e não operacionais (horas); TP = tempo programado para o trabalho (horas).

\section{Estimativa da produtividade}

A produtividade do skidder foi determinada por meio do volume médio individual das árvores com casca fornecido pelo inventário da empresa, cujo valor foi multiplicado pelo número de árvores extraídas nos ciclos operacionais e dividido pelas horas efetivamente trabalhadas, conforme a expressão proposta por Moreira (2004): 


$$
\mathrm{PR}=\frac{\mathrm{n} \times \mathrm{V}}{\mathrm{HE}}
$$

em que: $\mathrm{PR}=$ produtividade $\left(\mathrm{m}^{3} \mathrm{cc} \cdot \mathrm{h} \mathrm{e}^{-1}\right) ; \mathrm{n}=$ número de árvores extraídas em cada ciclo operacional; $\mathrm{V}=$ volume médio individual das árvores extraídas em cada ciclo operacional $\left(\mathrm{m}^{3} \mathrm{cc}\right) ; \mathrm{HE}=$ tempo efetivo de trabalho (horas).

\section{Fatores de influência na produtividade do skidder de cabo}

Existem diversos fatores que influenciam a produtividade do trator florestal skidder, sendo que, neste estudo, foram consideradas a distância de extração e a declividade do terreno. A espécie florestal e os operadores foram considerados como variáveis constantes no estudo, sendo estudada a espécie de Pinus taeda e operadores com experiência e desempenho semelhantes na operação de extração florestal, que foram previamente selecionados, conforme dados históricos da empresa.

Em relação à distância de extração (DE), considerou-se a distância fixa percorrida pela máquina desde o estaleiro até o limite de acesso no interior do talhão, com média de 25 metros, acrescidas das distâncias de guinchamento, cujo somatório resultou na estratificação da distância de extração em cinco níveis: I: DE $\leq 50$ m; II: $50<\mathrm{DE} \leq 75 \mathrm{~m}$; III: $75<\mathrm{DE} \leq 100 \mathrm{~m}$; IV: $>100 \mathrm{~m}$.

A declividade do terreno (DL) foi considerada como a inclinação média das trilhas de arraste, determinada por meio de clinômetro e estratificada em dois níveis (I: $0<\mathrm{DL} \leq 20^{\circ}$ e II: $20<\mathrm{DL} \leq 45^{\circ}$ ), sendo denominadas no trabalho como suave ondulado e acidentado, respectivamente.

Foi ainda obtido o número de árvores e volume de madeira arrastado em cada ciclo operacional da máquina nas diferentes condições de distância de extração e declividade.

\section{Análise estatística}

Os dados de produtividade da máquina nas diferentes distâncias de extração foram comparados entre si pelo teste Tukey, enquanto as diferentes declividades foram comparadas pelo teste $\mathrm{T}$, ambos ao nível de 5\% de probabilidade. Foi ainda analisada a relação entre a variável distância de extração e a produtividade em cada classe de declividade, por meio de uma análise de regressão, conforme expressão abaixo:

$$
\mathrm{Y}=\beta 0+(\beta 1 \mathrm{xDE})
$$

em que: $\mathrm{Y}=$ produtividade $\left(\mathrm{m}^{3}\right) ; \beta O, \beta 1=$ coeficientes; $\mathrm{DE}=$ distância de extração $(\mathrm{m})$.

Os coeficientes de determinação $\left(\mathrm{R}^{2}\right)$ foram utilizados para verificar quanto da variabilidade total dos dados de produtividade era explicada pela variável distância de extração nas diferentes classes de declividade.

\section{RESULTADOS E DISCUSSÃO}

\section{Estudos de tempos e movimentos}

No estudo, foi obtido um número de 689 ciclos operacionais de extração da madeira realizada pelo skidder de cabo, valor superior ao mínimo de 427 ciclos recomendados para obtenção de um erro de amostragem admissível de 5\%.

A distribuição percentual média dos tempos dos elementos do ciclo operacional do skidder de cabo é mostrada na figura 2. Como pode ser visto, entre os elementos efetivos da operação, o arraste do cabo principal e o engate nas correntes previamente fixadas na base das árvores consumiram $28 \%$ do tempo total do ciclo operacional. Tal fato foi ocasionado pela maior dificuldade de deslocamento dos auxiliares sobre o terreno declivoso para o arraste do cabo, desde a base da máquina posicionada no limite de acesso no interior talhão até base das árvores, cuja distância média variou de 25 a $75 \mathrm{~m}$. Em seguida, o desengate das correntes após o arraste das árvores consumiu $11 \%$ do tempo total, sendo ocasionado pela dificuldade de desengate das correntes que ficavam presas nas árvores arrastadas.

Em relação à viagem vazio (4\%) e viagem carregado (6\%), verifica-se que ambos os elementos consumiram um baixo tempo do ciclo operacional, sendo este um comportamento típico dessa operação com uso do skidder de cabo (chocker skidder), ao contrário do skidder de garra (grapple skidder), que

FLORESTA, Curitiba, PR, v. 45, n. 3, p. 625 - 634, jul. / set. 2015. 
passa a maior parte do tempo do ciclo operacional de forma ativa, ou seja, realizando as viagens vazia e carregada (SEIXAS, 2014; LOPES, 2014). Portanto, ficou evidente que, para a obtenção de maior produtividade e redução dos custos de produção em condições de terrenos declivosos com esse modelo de equipamento, torna-se necessária a melhoria do planejamento operacional, bem como o desenvolvimento de novos modelos de cabos e correntes, que favoreçam o arraste, engate e desengate das árvores durante a execução da operação.

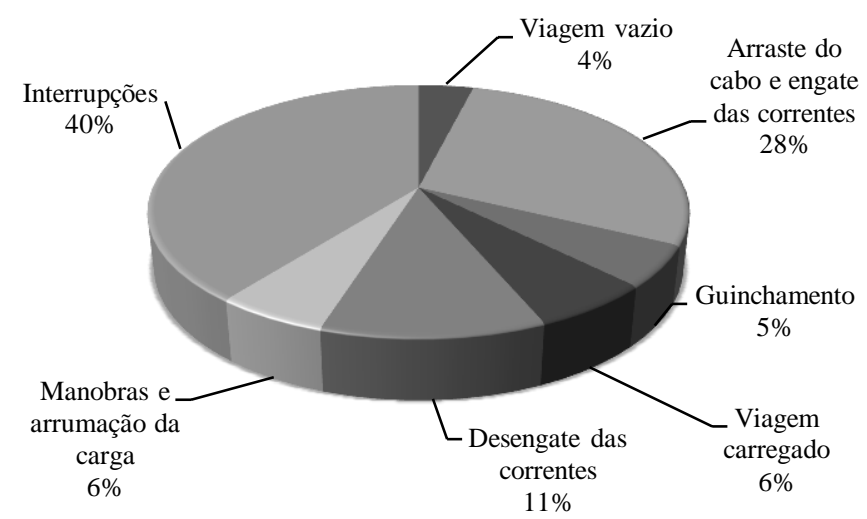

Figura 2. Composição percentual dos tempos do ciclo operacional do skidder de cabo. Figure 2. Percentage composition of the operational cycle of the chocker skidder.

As interrupções operacionais e não operacionais da extração da madeira durante a realização do estudo são apresentadas na tabela 2. É importante ressaltar que, entre as interrupções totais observadas (40\%), 80,5\% foram de caráter operacional, ou seja, relacionadas à operação propriamente dita, enquanto $19,5 \%$ foram relativas às interrupções não operacionais, sendo ambos os tempos passíveis de serem reduzidos com a implantação de melhorias no planejamento operacional.

Em relação às interrupções operacionais, a limpeza do estaleiro $(21,8 \%)$ e o deslocamento da máquina entre talhões $(18,8 \%)$ foram aquelas de maior ocorrência, estando relacionadas com a necessidade de melhorias no planejamento operacional, como a definição e melhorias dos estaleiros para depósito da madeira, a localização das árvores, a definição das rotas de extração e a sequência de corte dos talhões. Além disso, ficou evidente a necessidade do desenvolvimento de um modelo de microplanejamento, com elaboração de mapas específicos dos talhões de colheita, contemplando informações que possam auxiliar os operadores no momento de execução da operação, tais como distância e sentido de extração, ângulo e disposição das árvores, localização dos ramais e estaleiros, restrições operacionais, alinhamento do plantio etc.

A manutenção corretiva ocupou $20,2 \%$ do tempo total das interrupções, podendo ser relacionada com o baixo tempo destinado para as manutenções preventivas, que ocuparam apenas $6,1 \%$ do tempo total, sendo que a inversão nesse tempo poderá contribuir para o aumento da disponibilidade mecânica da máquina.

Além disso, destacam-se outras interrupções que não são normais à operação, como comunicação via rádio, apoio dos operadores de motosserra no corte de galhos que ficavam presos nas árvores no momento do arraste, corrente fixada nas árvores que ficava presa nos tocos no momento do arraste e manobras adicionais no descarregamento da madeira no estaleiro, que contribuíram, juntas, com $8,7 \%$ do tempo total das interrupções operacionais.

Com relação às interrupções não operacionais, a ocorrência de chuva e o deslocamento de pessoal ocuparam $52,0 \%$ e $21,7 \%$ do tempo total, respectivamente, sendo que tais tempos perdidos poderiam ser evitados, pois as condições climáticas são previsíveis e devem ser consideradas no planejamento operacional, com o estabelecimento de talhões estratégicos de colheita e melhor organização das equipes nas frentes de trabalho. 
Tabela 2. Distribuição percentual das interrupções operacional e não operacional do skidder de cabo.

Table 2. Percentage distribution of operational and non-operating interruptions of chocker skidder.

\begin{tabular}{lccc}
\hline & Interrupções & Tempo médio (min) & Tempo percentual (\%) \\
\hline Operacionais & Abastecimento da máquina & 40,1 & 2,6 \\
& Árvore presa & 70,9 & 4,7 \\
& Aguardando frente de trabalho & 41,5 & 2,7 \\
Aguardando máquina de apoio & 39,0 & 2,6 \\
& Check list da máquina & 96,2 & 6,3 \\
& Deslocamento entre talhões & 285,8 & 18,8 \\
Limpeza do estaleiro & 331,5 & 21,8 \\
Supervisão de campo & 25,9 & 1,7 \\
& Verificação da área de trabalho & 62,5 & 4,1 \\
Manutenção preventiva & 91,3 & 6,0 \\
& Manutenção corretiva & 307,3 & 20,2 \\
& Outros & 132,1 & 8,7 \\
\hline Não operacionais & Subtotal & - & 100,0 \\
& Deslocamento de pessoal & 80,3 & 21,7 \\
& Necessidades fisiológicas & 27,4 & 7,4 \\
& Lanche & 69,7 & 18,8 \\
& Chuva & 192,5 & 52,0 \\
\hline Subtotal & 369,9 & 100,0 \\
\hline & Total geral & - & 100,0 \\
\hline
\end{tabular}

\section{Disponibilidade mecânica, disponibilidade técnica e eficiência operacional}

A disponibilidade mecânica média do skidder de cabo obtida durante o estudo foi de $92,1 \%$, cujo valor foi elevado, apesar das manutenções corretivas realizadas durante a realização do estudo, por se tratar de uma máquina com baixa vida útil (1.057 horas) e com pouca necessidade de intervenções mecânicas. Por outro lado, a disponibilidade técnica foi de apenas $66,0 \%$, ocasionada pelo elevado tempo de interrupções operacionais e não operacionais ocorridas durante a execução da operação, acarretando, consequentemente, uma eficiência operacional média de apenas $60,7 \%$. Tal valor pode ser considerado baixo quando comparado ao obtido por outros autores, como Santos et al. (2013), que, estudando um clambunk skidder na extração de madeira do híbrido Eucalyptus urophylla x Eucalyptus grandis com 7 anos de idade, volume de 404,2 $\mathrm{m}^{3} \cdot \mathrm{ha}^{-1}$ e em relevo plano, obtiveram uma eficiência operacional média de 78,3\%, enquanto Fiedler et al. (2008), estudando um skidder de garra no arraste de árvores de Eucalyptus grandis com 8 anos de idade, com volume médio de $256 \mathrm{~m}^{3} \cdot \mathrm{ha}^{-1}$ e em relevo plano, obtiveram uma eficiência operacional de $73,2 \%$.

Portanto, os resultados obtidos reforçam a necessidade do estabelecimento de medidas imediatas para a otimização da operação, por meio da implantação de um modelo eficiente de planejamento e controle das operações, principalmente em relação ao microplanejamento.

\section{Estimativa da produtividade}

Na figura 3 é mostrada a produtividade do skidder de cabo nas diferentes distâncias de extração e classes de declividade do terreno. Como pode ser visto, em ambas as declividades de terreno, a produtividade média decresceu com o aumento da distância de extração, sendo significativa pelo teste de Tukey ao nível de 5\% de probabilidade. Tal resultado foi ocasionado pelo maior tempo para completar o ciclo operacional, em decorrência das dificuldades operacionais nas condições de terrenos declivosos e do elevado tempo de engate e desengate dos cabos nas árvores.

A produtividade média da máquina foi de apenas $17,56 \mathrm{~m}^{3} \mathrm{cc} \cdot \mathrm{he}^{-1}$ e $11,92 \mathrm{cc} \cdot \mathrm{he}^{-1}$ nas classes de declividade I e II, respectivamente, com diferença significativa pelo teste $\mathrm{T}(\mathrm{p}<0,05)$. Tais resultados estão abaixo do obtido por Santos et al. (2013), que, estudando um clambunk skidder, obtiveram uma produtividade de $80,3 \mathrm{~m}^{3} \mathrm{cc} \cdot \mathrm{Ce}^{-1}$ em um povoamento de eucalipto na distância média de extração de 241,2 m, e por Fiedler et al. (2008), que, estudando um skidder de garra na extração de madeira de

FLORESTA, Curitiba, PR, v. 45, n. 3, p. 625 - 634, jul. / set. 2015. 
eucalipto, obtiveram uma produtividade de $42,3 \mathrm{~m}^{3} \mathrm{cc} \cdot \mathrm{e}^{-1}$ para uma distância média de arraste de 230 metros.

Ao se analisar a influência das variáveis declividade do terreno e distância de extração sobre a produtividade do skidder de cabo, foi possível constatar que houve uma redução da produtividade da máquina em função do aumento da declividade e da distância de extração, situação de comum ocorrência nessa operação. Entretanto, como pode ser visto na figura 3, a declividade do terreno afetou de forma mais significativa a produtividade da máquina nas menores distâncias de extração, sendo que nas classes de distância até $100 \mathrm{~m}$ houve diferença significativa na produtividade da máquina entre as classes de declividade, enquanto na distância acima de $100 \mathrm{~m}$ não houve diferença significativa na produtividade entre as classes de declividade pelo teste $\mathrm{T}(\mathrm{p}<0,05)$.

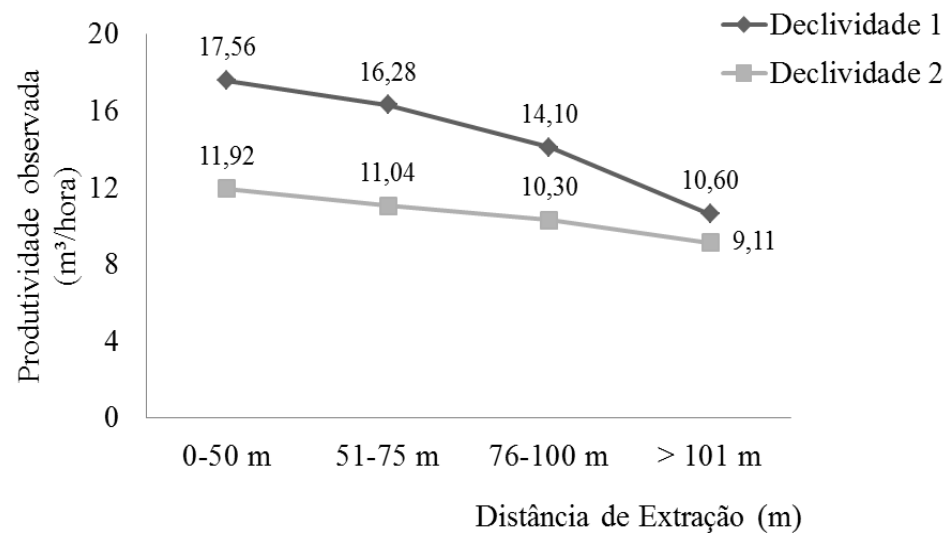

Figura 3. Produtividade do skidder de cabo nas diferentes declividades e distâncias de extração.

Figure 3. Productivity of the chocker skidder at differents slopes and extraction distances.

O comportamento da produtividade observada e estimada do skidder de cabo nas diferentes distâncias de extração e declividades do terreno é apresentado na figura 4, considerando-se um volume médio de extração observado de $4,7 \mathrm{~m}^{3}$ e $3,3 \mathrm{~m}^{3}$ ou 4,3 e 3,0 árvores/ciclo operacional nas declividades suaves onduladas e declivosas (I e II), respectivamente.
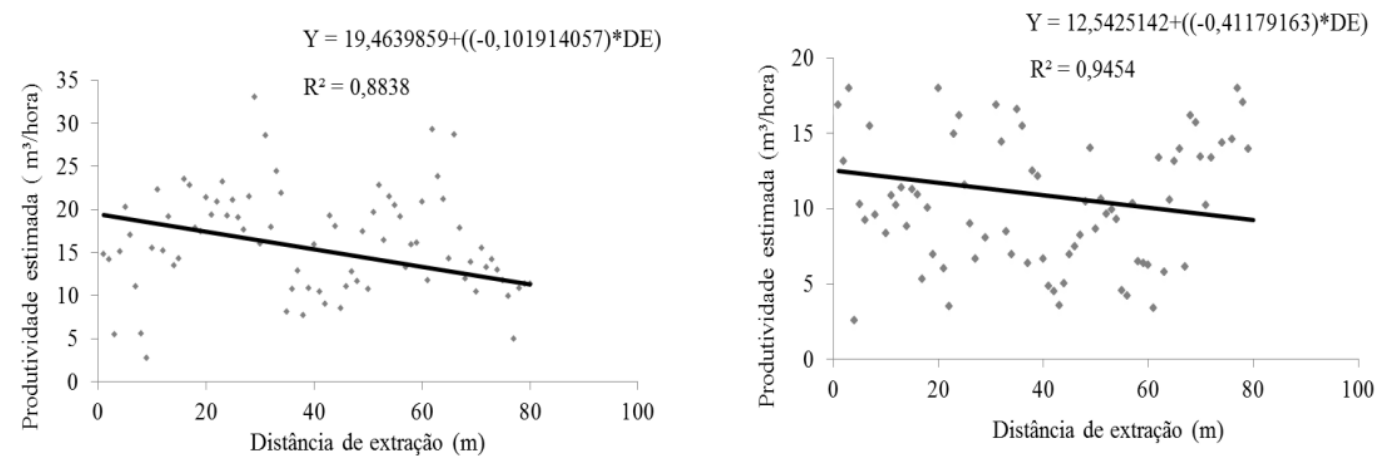

Figura 4. Produtividade observada e estimada do skidder de cabo nas declividades de 0 a $20^{\circ}$ (a) e 20 a $45^{\circ}(\mathrm{b})$.

Figure 4. Observed and estimated productivity of the chocker skidder on slope degree 0 a $20^{\circ}$ (a) e 20 a $45^{\circ}$ (b).

Analisando os dados, observa-se que o aumento da distância de arraste ocasionou uma queda na produtividade em ambas as classes de declividade, sendo de forma mais pronunciada na classe de 0 a $20^{\circ}$ de declividade, estando ainda os resultados coerentes com a tendência encontrada nos valores observados.

As equações foram consideradas aceitáveis para estimar a produtividade do trator florestal skidder de cabo nas diferentes distâncias de extração e classes de declividade, sendo que, na classe de 
declividade suave ondulado, a variável distância de extração explicou $88,4 \%$ da produtividade da máquina, enquanto na maior declividade do terreno explicou $94,5 \%$ da produtividade.

\section{CONCLUSÕES}

Os resultados e discussões desta pesquisa permitiram concluir que:

- Os elementos parciais "engate e desengate" consumiram o maior tempo percentual do ciclo operacional da extração de madeira com o skidder de cabo, contribuindo para a baixa produtividade da máquina nas condições de terrenos declivosos.

- A baixa disponibilidade técnica e eficiência operacional mostrou a necessidade da implantação de melhorias no modelo atual de planejamento da operação de extração da madeira.

- A produtividade da máquina foi mais afetada pela declividade do terreno nas menores distâncias de extração, mostrando a maior sensibilidade dessa variável nessa condição operacional.

- O aumento da distância de extração e declividade do terreno contribuiu para a redução da produtividade do skidder de cabo, devendo tais variáveis ser consideradas no planejamento das operações florestais em terrenos declivosos.

\section{REFERÊNCIAS}

BARNES, R. M. Estudo de movimentos e de tempos: projeto e medida do trabalho. 6. ed. São Paulo: E. Blucher, 1977. $635 \mathrm{p}$.

BRAMUCCI, M.; SEIXAS, F. Determinação e quantificação de fatores de influência sobre a produtividade de "harvesters" na colheita florestal. Scientia Forestalis, Piracicaba, n. 62, p. 62 - 74, 2002.

FIEDLER, N. C.; ROCHA, E. B.; LOPES, E. S. Análise da produtividade de um sistema de colheita de árvores inteiras no norte do estado de Goiás. Floresta, Curitiba, v. 38, n. 4, p. 577 - 586, 2008.

LOPES, E. S. Aplicação do programa SNAP III (Scheduling and Network Analysis Program) no planejamento da colheita e do transporte florestal. $150 \mathrm{f}$. Tese (Doutorado em Ciência Florestal) Universidade Federal de Viçosa, Viçosa, 2001.

LOPES, E. S.; OLIVEIRA, D.; SAMPIETRO, J. A. Influence of wheeled types of a skidder on productivity and cost of the forest harvesting. Floresta, Curitiba, v. 44, n. 1, p. 53 - 62, 2014.

MACHADO, C. C. Colheita Florestal. 3. ed. Viçosa: Ed. UFV, 2014. 543 p.

MOREIRA, F. M. T.; SOUZA, A. P.; MACHADO, C. C.; MINETTI, L. J.; SILVA, K. R. Avaliação operacional e econômica do "feller-buncher" em dois subsistemas de colheita de florestas de eucalipto. Revista Árvore, v. 28, n. 2, p. 199 - 205, 2004.

OLIVEIRA, D.; LOPES, E. S.; FIEDLER, N. C. Avaliação técnica e econômica do forwarder na extração de toras de pinus. Scientia Forestalis, Piracicaba, v. 37, n. 84, p. 525 - 533, 2009.

ROCHA, E. B.; FIEDLER, N. C.; ALVES, R. T.; LOPES, E. S.; GUIMARÃES, P. P.; PERONI, L. Produtividade e custos de um sistema de colheita de árvores inteiras. Cerne, Lavras, v. 15, n. 3, p. 372 381, 2009.

SANTOS, P. H. A.; SOUZA, A. P.; MARZANO, F. L. C.; MINETTE, L. J. Produtividade e custos de extração de madeira de eucalipto. Revista Árvore, Viçosa, v. 37, n. 3, p. 511 - 518, 2013.

SEIXAS, F. Extração. In: MACHADO, C. C. Colheita florestal. 3 ed. Viçosa: Ed. UFV, 2014. 543 p.

SILVA, C. B.; SANT ANNA, C. M.; MINETTE, L. J. Avaliação ergonômica do feller-buncher utilizado na colheita de eucalipto. Cerne, Lavras, v. 9, n. 1, p. 109 - 118, 2003.

SIMÕES, D.; FENNER, P. T.; BANTEL, C. A. Custo e rendimentos operacionais da extração de madeira de eucalipto com cabo aéreo. Cerne, Lavras, v. 16, n. 2, p. 185 - 192, 2010.

STUDIER, D. D.; BINKLEY, W. V. Cable Logging Systems-DTM/Pacific Northeast Station. Forest Service - USDA: Oregon, 1974. 210 p. 
FLORESTA, Curitiba, PR, v. 45, n. 3, p. 625 - 634, jul. / set. 2015. Lopes, E. da S.; Diniz, C. C. C. 